\title{
SUSTAINED YIELDS FROM CANADIAN FORESTS
}

Some of the papers on this subject, presented at the Annual Meeting in Victoria, were reproduced in the last issue of the Chronicle. The discussion paper prepared by Mr. J. E. Guay, of the Quebec Forest Service, was not available for publication at that time, but an abstract of same is now pre. sented, together with some portions of the comments made by various individuals from the floor. The Editor.

\section{BY J. E. GUAY', Provincial Forest Service, Quebec}

$\mathrm{T}$

HE REQUIREMENTS of the preliminary investigations, once the working circle or operating unit requirements, whichever is the controlling factor, together with the market conditions, have been determined, are set out. A point of local experience emphasized by the author concerns the permanence of the lease-title in the case of Crown timber lands, during such time as lands may be withdrawn for colonization and other purposes. Protection should be acquired by a "Guarantee that, if, for motives of national interest, forested land is taken out of the managed forest, fair compensation will be given for any work done to improve the forest property."

Having answers to the questions of mill requirements, markets, exploitation methods, and having assurance of protection from fire, insect and fungus attacks, the next step is to proceed to the woods for the working plan survey. After discussing the boundaries and subdivisions of the working circle or unit, topography, site types, cover types and age classes, the author refers to the influence of the last three factors on the increments for each species of each subdivision of the unit, as the net annual increment controls the amount of the cutting budget.

Next, the working plan provides for the removal of an annual budget not in excess of the average annual increment and without impairing the increment and reproduction. It includes a satisfactory site-type classification based on ground vegetation, which the Dominion Forest Service has foun] to correspond closely to growth variations due to variations in topography as well as the age-height classifications.

In Quebec an amendment to the Woods and Forests Regulations in 1939 prescribed that, while every license holder has the right to cut trees which are $12^{\prime \prime}$ or more in diameter at $2^{\prime}$ from the ground, with some exceptions, he must keep within the capacity of the Crown forest under licence, and operations must be carried out in conformity with a general working plan prepared according to law.

The licence holder must furnish, in addition to the working plan for the whole area, a special working plan for the sector to be operated during the first decade. The cutting operations must be subordinate in particular to the following abbreviated prescriptions:

(a) The ten-year cut shall be as prescribed in the special working plan, and shall not exceed the possibility for the period, except where it is judged opportune to regularize the forest stock.

1. Abstracted by Eric Garman, Chairman, Victoria Section, C.S.F.E. 
(b) The cutting program for each season must be submitted to the Minister at least three months in advance.

(c) Sectors to be cut as provided in special working plan must be previously examined jointly by forest engineers of licence holder and the Department of Lands and Forests to choose from the Silvicultural treatments in the working plan the one preferable for use in each case.

(d) No cuts, except thinnings, will be tolerated in stands less than 60 years of age.

(e) The names of persons charged with supervision of the cuts, who will work together with representatives of the Government to see that the working plan is followed.

(f) The licence holder must exploit damaged stands first.

(g) A plan of areas cut shall be submitted to the Minister during the following year.

The general working plan must be revised each decade and a special working plan approved by the Minister of Lands and Forests before being put into execution.

The Minister may make special regulations for operations for which no working plan has been submitted, and the costs of management of these forests are charged to the licence holder.

The annual program required by prescription (b) in the above regulations is stipulated in the excerpt below from a circular to operators of limits requiring them to transmit to the Chief of the Forest Service a type map in duplicate showing the exact location of each block of forest in which cutting operations are to take place, together with a report (also in duplicate) giving the following information for each block or group of blocks identical in composition and site-quality.

1. The designation of the location of each block of forest.

2. Area in acres of each block of forest and the amount of wood to be cut therein.

3. Topographical data.

4. Comments on each of the forest types, their respective areas, their ages and the percentage of each of the species of which they are composed.

5. Average composition of each forest type, viz.: Number of trees per acre for each species by inch classes (D.B.H.).

6. Estimation of the forest (total volume for each of the three principal diameter-classes: $4^{\prime \prime}$ and up, $6^{\prime \prime}$ and up, $9^{\prime \prime}$ and up (D.B.H.).

7. Reproduction by species for each type (average height and number of stems per acre, etc.).

8. Special difficulties in logging (average distance of hauling, etc.).

9. Proposed methods of cutting for each forest type or sub-type.

10. Reasons justifying these cutting-systems.

Besides the information suggested in the first paragraph the type-map required must also show the areas cut-over during the previous season.

As required by the law, this report and this plan must be prepared by $a$ recognized Forest Engineer of the Province of Quebec. 